\title{
Evaporation from Surface Deposited Thickened Gold Tailings
}

\author{
P. Simms Carleton University, Ottawa, Canada \\ M. Grabinsky University of Toronto, Toronto, Canada \\ G. Zhan Barrick Gold Corporation, Salt Lake City, United States
}

\section{INTRODUCTION}

The rate of evaporation from thickened tailings is an important parameter for the management of surface deposition. Promoting evaporation in a freshly-deposited layer is desirable up to a point, since evaporation causes densification and strength gain, but excess evaporation will desaturate the tailings and consequently increase the risk of acid generation. Therefore, the ability to predict the rate of evaporation to some degree of accuracy would be a substantial advantage in deposition planning. This study, part of a larger project researching the surface deposition of non-plastic, thickened tailings at the Bulyanhulu Gold Mine in Tanzania, investigates drying from thickened gold tailings in the laboratory and in the field. Material presented in this paper includes laboratory comparison of evaporation from a small column $(0.3 \mathrm{~m}$ diameter by $0.2 \mathrm{~m}$ in height) to evaporation from larger-scale tests $(2 \mathrm{~m}$ by $1 \mathrm{~m}$ in plan and $0.1 \mathrm{~m}$ in thickness) performed on tailings from Bulyanhulu. These laboratory results are compared with field measurements.

\section{BACKGROUND}

The drying of slurry tailings after deposition is known to be complicated by several factors, such as selfweight consolidation, cracking and the influence of salts (Fujiyasu et al., 2000; Fujiyasu and Fahey, 2000). It was originally thought that the thickened Bulyanhulu tailings (percentage solids $>70 \%$, Plasticity Index $<$ 1) would exhibit little self-weight consolidation, and be only marginally affected by cracking and salts compared to slurried tailings. However, subsequent results (Simms et al., 2005) have shown that these factors may also play an important role in the Bulyanhulu tailings that have to be accounted for in optimized design. Salts can reduce drying by vapour suppression, their precipitation as a crust, and by increasing albedo. Cracking may increase the overall rate of evaporation by increasing the amount of surface area directly in contact with the atmosphere.

One of the goals of the project was to see if drying rates measured in the laboratory and the field could be estimated using a one-dimensional coupled soil-atmosphere unsaturated flow model, such as SoilCover (Wilson et al., 1994). To that end, an evaporation test was performed on a small column of tailings instrumented with matric suction sensors, which was placed on a scale to determine the rate of evaporation. As Simms and Grabinsky (2004) postulated that albedo might play a significant role in evaporation, a larger 
test was devised of sufficient plan area to facilitate the measurement of albedo (Simms and Grabinsky, 2004). Results of the first larger-scale test with a pan evaporation of approximate $2 \mathrm{~mm} /$ day are detailed in Simms et al. (2005) and show that, although there is a variability in albedo $(0.10-0.18)$, it is likely to be only of marginal importance in predicting field evaporation rates for the Bulyanhulu tailings. A second test was performed at a higher rate of pan evaporation of approximate $10 \mathrm{~mm} /$ day. In this paper, the results of a small column test are presented, along with a comparison of albedo measurements from the two larger-scale tests. Both tests are compared to field measurements taken during the summers of 2004 and 2005 at the Bulyanhulu mine.

\section{METHOD}

In the larger-scale tests, tailings were deposited in a $0.1 \mathrm{~m}$ deep by $1 \mathrm{~m}$ by $2 \mathrm{~m}$ layer in a box (Figure 1). Any supernatant water from self-weight consolidation was not drained off, but rather evaporated off under the controlled microclimatic conditions. Different from the first larger-scale test, wind was simulated in the second experiment by a fan attached to one side of the box. The box is $1 \mathrm{~m}$ tall and its walls were painted black so as to minimize reflection.

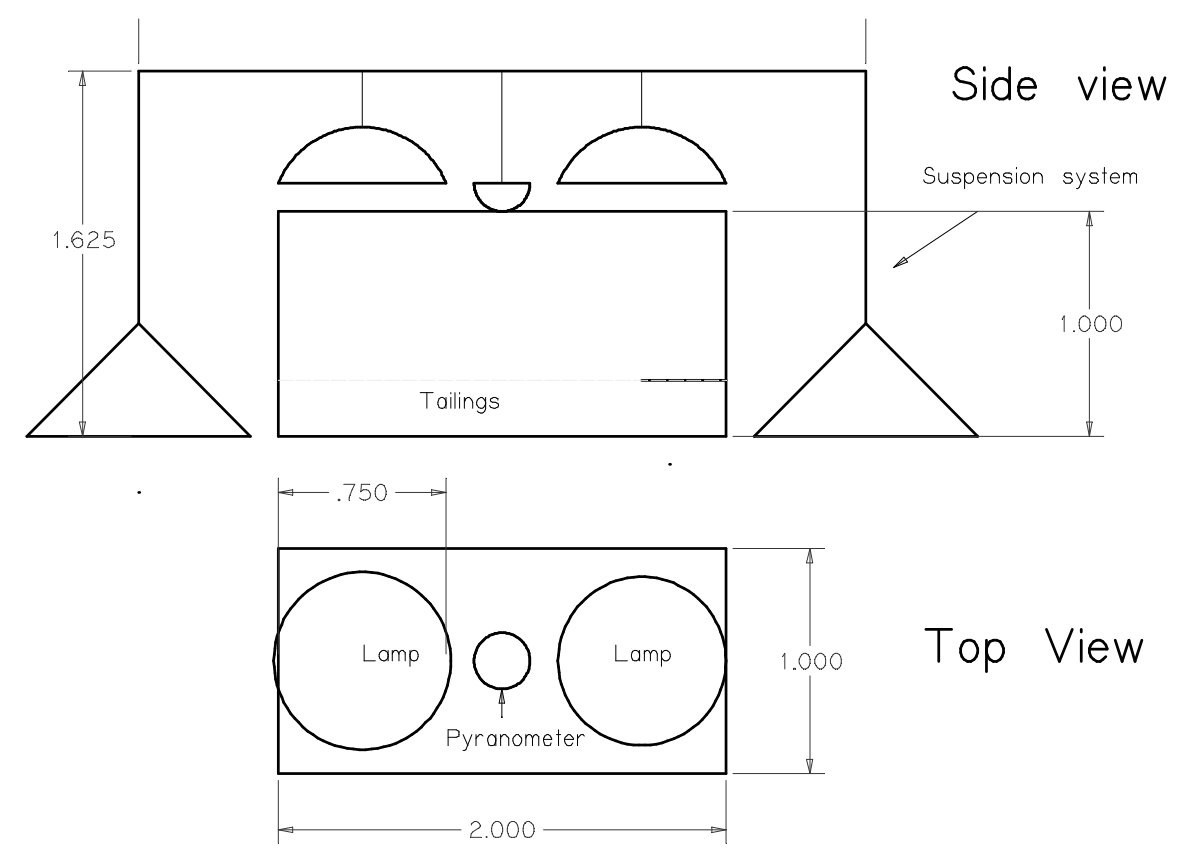

\section{Figure 1 Schematic of larger drying test (units are in $\mathbf{m}$ )}

Two $400 \mathrm{~W}$ metal halide lamps, positioned $1 \mathrm{~m}$ above the surface were used to generate radiation. The reflected radiation from the tailings was measured using a pyranometer, which was also suspended approximately $1 \mathrm{~m}$ above the tailings surface. The incoming short-wave radiation from the lamps was initially measured at different points at the bottom of the box under the lamps, and was found to be relatively uniform ( $+/-10 \%$ of mean). The average value of incoming shortwave radiation was $2.5 \mathrm{MJ} / \mathrm{m}^{2}$. Relative humidity and air temperature were measured by a sensor mounted on one of the interior walls of the box, and 
varied between 25 and $30 \% \mathrm{RH}$ and 30 to $35^{\circ} \mathrm{C}$ respectively. Instantaneous wind speed was highly variable within the box, but pan evaporation from different parts of the box was fairly uniform at about 10 $\mathrm{mm} /$ day. This value of PE corresponds to the average PE at the site from July to October 2004, calculated from weather data collected at a weather station at the mine. The highest monthly averaged PE was $18.5 \mathrm{~mm}$ per day for July 2004.

The small column drying test was conducted under the same environmental conditions as the second largerscale test. The small column test comprised of tailings poured into a cylinder of $0.3 \mathrm{~m}$ diameter and $0.2 \mathrm{~m}$ depth, mounted on a scale, all of which was placed inside the large box used for the larger-scale tests. The vertical settlement was recorded as well as the mass, and suctions sensors placed near the top (1 tensiometer [T5] sensor and 1 heat dissipation [HD] sensor) and bottom (1 HD sensor). The initial thickness of material for the tailings was approximately $0.2 \mathrm{~m}$.

\section{RESULTS}

Figure 2 shows the apparent albedo measured in the two larger-scale tests. It can be seen that the slightly higher values were recorded during the second test, which had a higher rate of evaporation of $10 \mathrm{~mm} / \mathrm{day}$. It is believed that this occurred due to the deposition of a white precipitate at the surface of the tailings that was observed during the second test, but not during the first test. The higher rate of evaporation would have increased the total mass of salts brought to the surface, resulting in a more noticeable amount of precipitation.

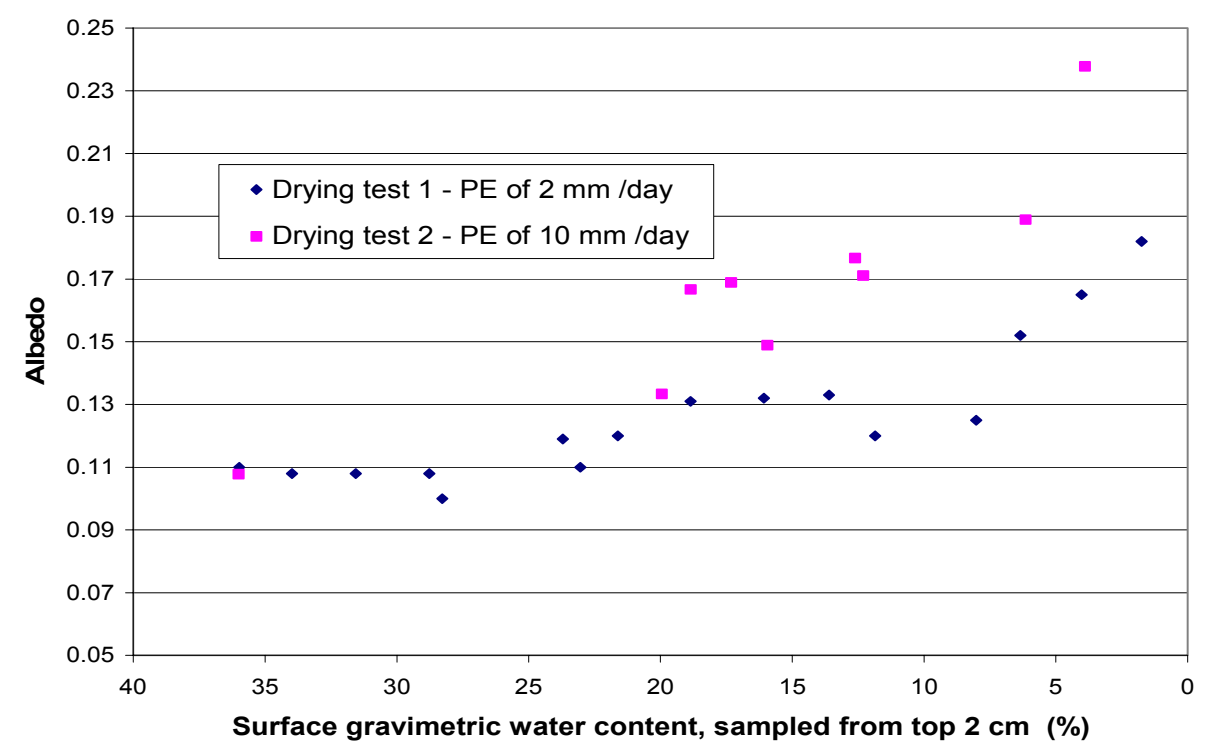

Figure 2 Laboratory measured albedo values versus gravimetric water content 
Albedo values were also measured in the field by a University of Toronto engineering student during the summer of 2005. Gravimetric water contents were collected close to the field pyranometer, sampled from the top 5 centimetres of the tailings beach. The recorded values are shown in Figure 3. It can be seen that at first there is an initial correlation between decreasing gravimetric water content and increasing albedo, but by late July the water contents settle to a steady state while the albedo keeps increasing. It is believed that salt precipitation is responsible for the continued increase in albedo, and the formation of a white precipitate was noticed at the site since deposition started (Golder, 2005). The high value of albedo measured in the field and the laboratory are close in value, however, the highest values of albedo measured in the laboratory were measured at a water contents less than $5 \%$, while similar values at the field were measured for water contents greater than $20 \%$ If the albedo changes only from 0.1 up to 0.2 , the effect on the evaporation rate will be small $(<10 \%)$.

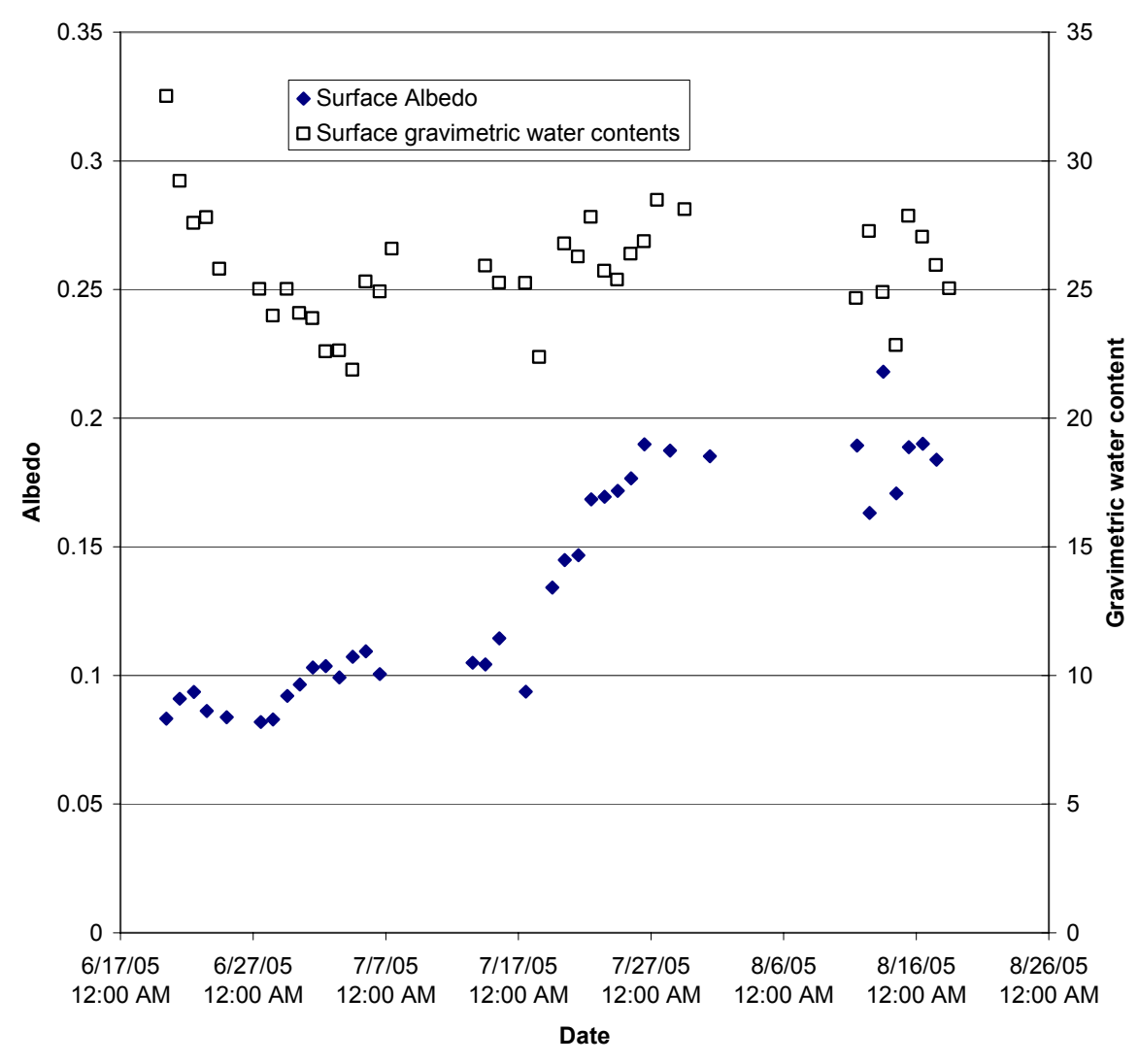

Figure 3 Albedo and surface gravimetric water contents (sampled from top $5 \mathrm{~cm}$ ) measured at Bulyanhulu

The results of the small column evaporation test are shown in Figures 4 and 5. Figure 4 compares measured cumulative evaporation with predictions using the SoilCover model, assuming a constant albedo of 0.12 over the course of the experiment. The measured values follow the classic evaporation curve, with an initial period in which the evaporation rate is close to the potential evaporation rate, followed by the moisturelimiting period in which evaporation decreases to some residual value. Figure 4 shows two numerical 
predictions of cumulative evaporation, one employing a saturated hydraulic conductivity of $2.0 \times 10^{-6} \mathrm{~cm} / \mathrm{s}$, a value obtained from independent laboratory measurements on the Bulyanhulu tailings (Crowder, 2004), and a value 5 times larger of $1.0 \times 10^{-5} \mathrm{~cm} / \mathrm{s}$, which gives the best match with the measured evaporation. It could be argued that the hydraulic conductivity value used in the modelling that gave the closest match between measured and predicted evaporation has a physical meaning, in terms of macroscopic attributes of the tailings not picked up in the laboratory hydraulic conductivity tests using small cores; however, the difference between numerical and measured results might just as easily be attributed to errors in the Soil Water Characteristic Curve.

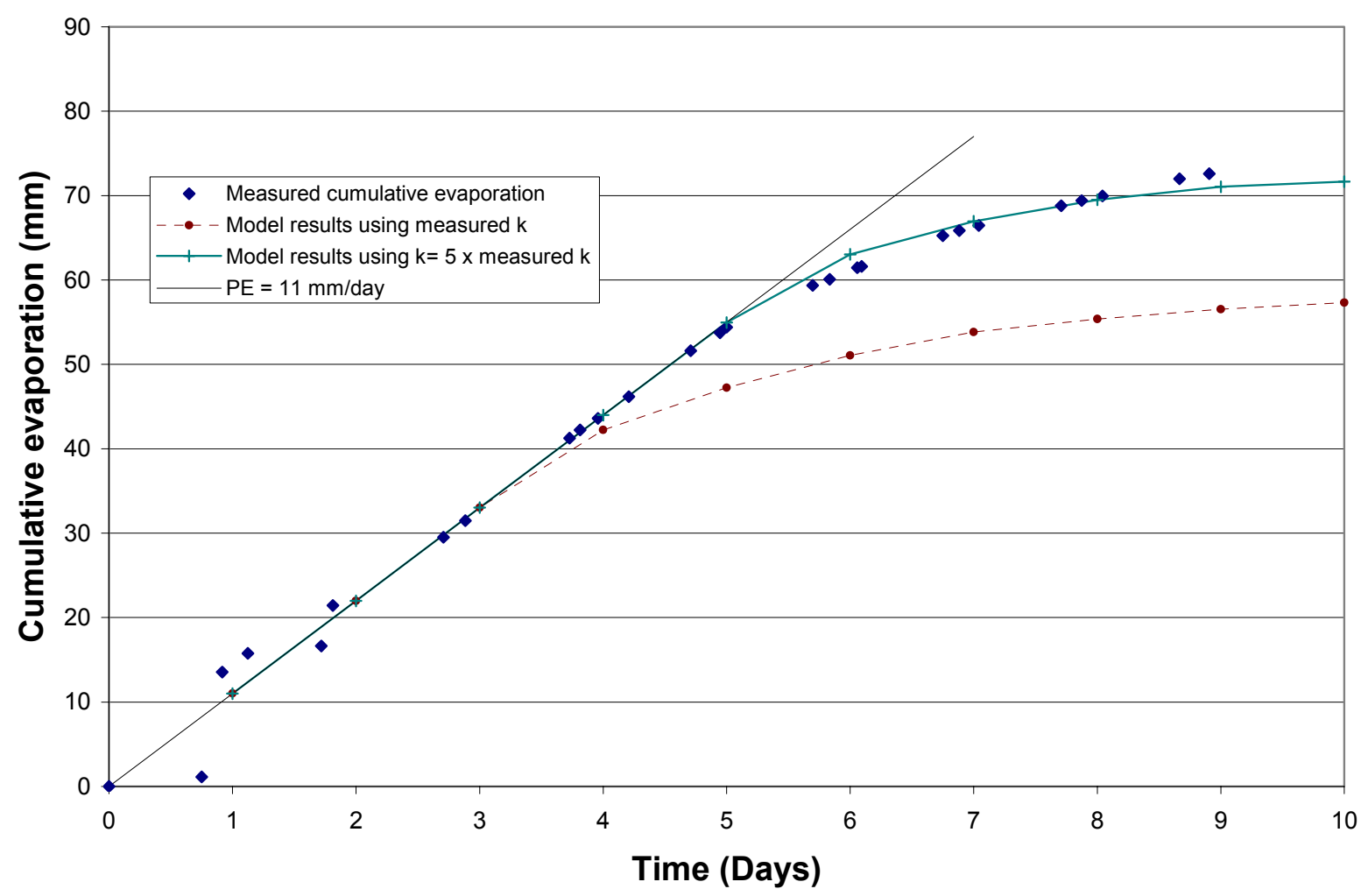

\section{Figure 4 Measured and modelled cumulative evaporation from the smaller evaporation test}

Figure 5 shows measured and modelled suctions. The suctions reported by the T5 sensor cavitated at 210 $\mathrm{kPa}$ on about day 7. The initial values (about $10 \mathrm{kPa}$ ) reported by the HD sensor are merely the air-entry values of their ceramic cups as they cannot register suctions below this amount. The T5 data generally lies above the top HD sensor data. Although T5 and the top HD sensor were initially placed at about $1 \mathrm{~cm}$ below the tailings surface, small ambiguity in placement would be enough to account for the variability between the sensors, without even accounting for possible shifting of the sensors during settlement of the tailings. On Figure 5, the measured suction profiles are more uniform with regard to depth than those predicted by the 
model. This may be due to the onset of micro cracking, which would cause a more uniform suction distribution due to two-dimensional drying.

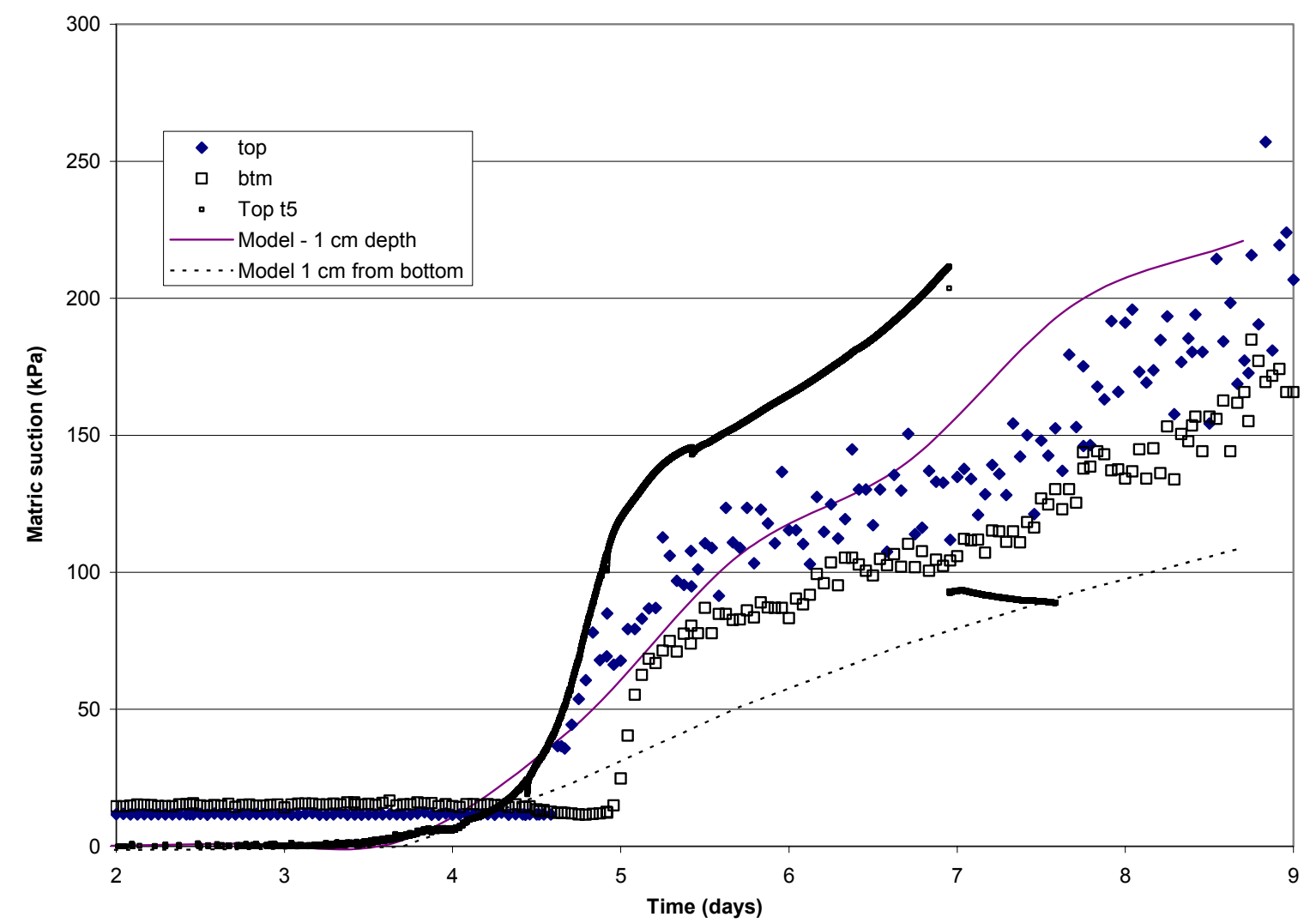

\section{Figure 5 Measured and modelled matric suctions at the top and bottom of the smaller evaporation test}

It is interesting to compare the predictions of SoilCover against field measurements of gravimetric water content as shown on Figure 6. The field measurements were taken on tailings beaches with an average thickness of $0.05 \mathrm{~m}$. The model predictions employ the saturated hydraulic conductivity obtained from fitting the laboratory test data to SoilCover predictions. A no-flow boundary condition was assumed at the bottom of the tailings. As seen in Figure 6, the predictions and the measured values have reasonable agreement, though the rate of evaporation seems to be underestimated during the first week. Though water pans placed on the tailings beach in 2005 during the first two weeks recorded a PE of $10 \mathrm{~mm} /$ day, the estimate of PE from weather station data is slightly higher at $13 \mathrm{~mm} /$ day. The water pans were only placed at one location, whereas the gravimetric water contents shown in Figure 6 are an average of samples obtained over a $50 \mathrm{~m}$ distance. Therefore, it is possible that the PE might be slightly underestimated in the model, which would explain the initially higher values of predicted water content. 


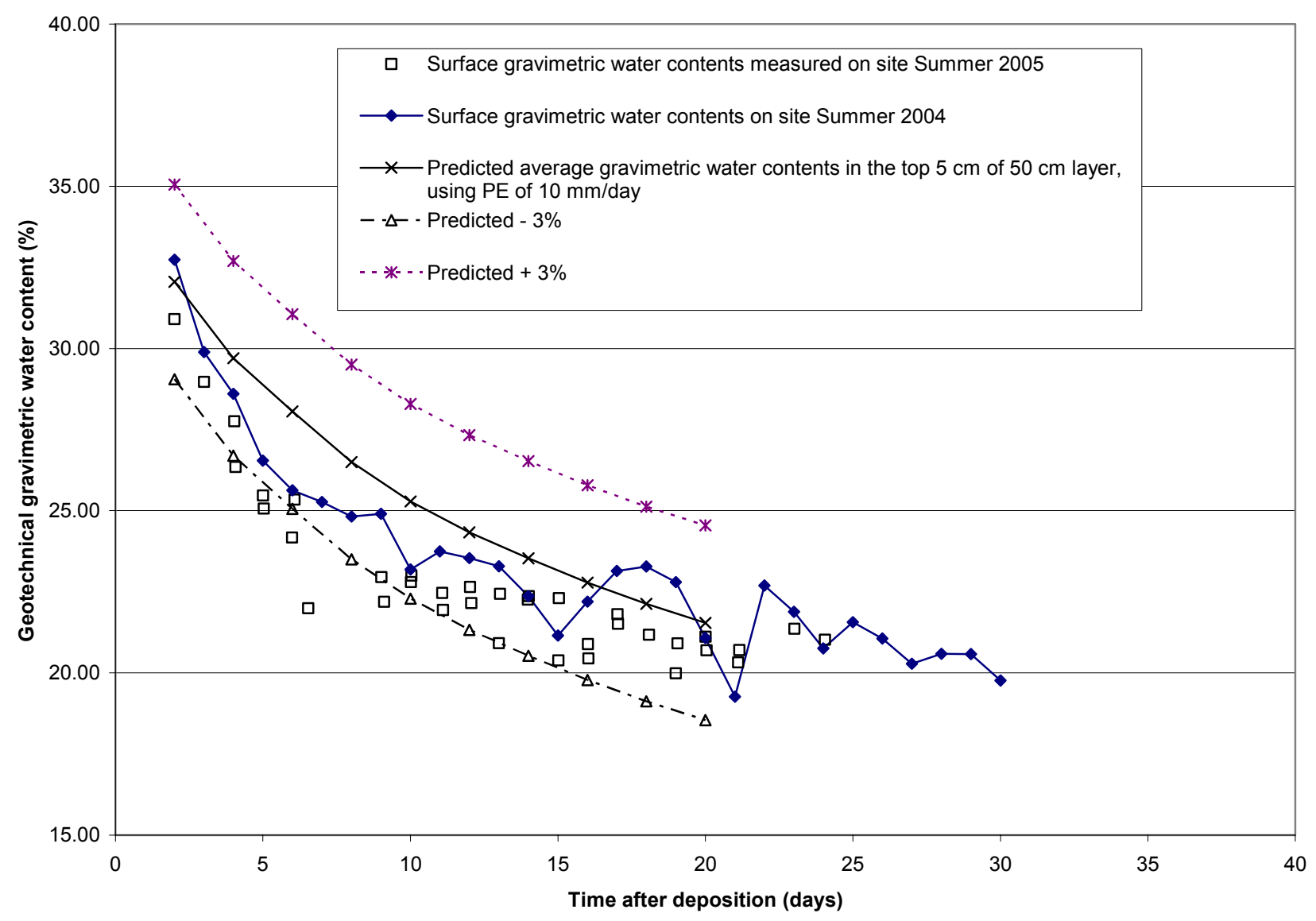

\section{Figure 6 Measured and modelled gravimetric water contents at Bulyanhulu in the summers of 2004 and 2005}

\section{CONCLUSIONS}

Strictly speaking, the degree of desiccation cracking and the generation of salt precipitates are at least two of the factors that must be reproduced in the laboratory in order to appropriately simulate field conditions. Although precipitates were formed both in the laboratory and in the field, this did not have an appreciable overall effect on the surface albedo and, in particular on the predicted rate of evaporation for the current case. Despite discrepancies between laboratory results and model predictions, measured and modelled gravimetric water contents at the site during the past two summers showed reasonable agreement. This result is encouraging as it suggests that the proposed approach may be used to assist in deposition planning at Bulyanhulu, though further comparisons between model results and field measurements are required to quantify the accuracy of the method. A more general method of predicting evaporation from thickened tailings will likely require further efforts to incorporate the influence of cracking and salts into numerical models. 


\section{ACKNOWLEDGEMENTS}

This research was partially funded by Barrick Gold Corporation. The field data were obtained by University of Toronto Undergraduates Akber Pabani and Nell Khakoo, who were employed by Barrick for the summers of 2004 and 2005 at the Bulyanhulu site. The staff at Bulyanhulu provided essential support to these students.

\section{REFERENCES}

Crowder, J.J. (2004) Deposition, consolidation, and strength of a non-plastic tailings paste for surface disposal. Doctoral Thesis, University of Toronto.

Fujiyasu, Y. and Fahey, M. (2000) Experimental study of evaporation from saline tailings, Journal of Geotechnical and Geoenvironmental Engineering 126(1) 18-27.

Fujiyasu, Y., Fahey, M. and Newson, T. (2000) Field investigation of evaporation from freshwater tailings. Journal of Geotechnical and Geoenvironmental Engineering 126(6) 556-567.

Golder Associates Africa (Golder) (2005) Report on Bulyanhulu Gold Mine Tailings Storage Facility Optimization of Deposition. Report No. 5098/6586/5/S

Simms, P.H, and Grabinsky, M.W. (2004) A simple method for estimating rates of drying and desaturation of paste tailings during surface depostion. Proceedings of the $11^{\text {th }}$ annual conference on Tailings and Mine Waste, October 10-13th 2004, pp. $287-292$.

Simms, P.H., Grabinsky, M.W. and Zhan, G. (2005) Laboratory evaluation of evaporative drying from surface deposited thickened tailings at the Bulyanhulu gold mine. Canadian Geotechnical Conference, Saskatoon, Saskatchewan, Sept. 18-21 2005 (Electronic proceedings).

Wilson, G.W., Fredlund, D.G. and Barbour, S.L. (1994) Coupled soil-atmosphere modeling for soil evaporation. Canadian Geotechnical Journal 31, pp. 151-161. 